\title{
BRIDGE OPTIMIZATION FOR THERMISTOR MEASUREMENTS
}

\author{
By B. BARry Narod \\ (Department of Geophysics and Astronomy, University of British Columbia, 2075 Wesbrook \\ Place, Vancouver, British Columbia V6T i $\mathrm{W}_{5}$, Canada)
}

\begin{abstract}
An expression for optimum bridge parameters is derived for a thermistor in a Wheatstone bridge and numerical values are assigned to determine the useful limits of resistance bridges for thermistor measurements. Several digital ohmmeters are evaluated as measuring devices and are shown to compare unfavourably with a simple bridge and null detector.

RÉsumÉ. Optimization d'un pont de mesures a thermistor. On établit une expression pour les paramètres d'un pont optimum pour un thermistor inclu dans un pont de Wheatstone et l'on donne des valeurs numériques pour déterminer les limites utilisables des ponts à résistance pour des mesures au thermistor. Plusieurs ohmètres digitaux sont jugés en tant que dispositif de mesure et l'on montre que la comparaison ne leur est pas favorable avec un simple pont à mesure de zéro.

Zusammenfassung. Optimierung der Widerstandsbrücke für Thermistor-Messungen. Für einen Thermistor in einer Wheatstoneschen Brücke wird ein Ausdruck für optimale Brückenparameter hergeleitet. Zur Bestimmung der zweckmässigen Bemessung von Widerstandsbrücken für Thermistor-Messungen werden Zahlenwerte angegeben. Als Messvorrichtung werden verschiedene digitale Ohmmeter untersucht, wobei sich zeigt, dass sie im Vergleich mit einer einfachen Brücke und einem Null-Detektor ungünstig abschneiden.
\end{abstract}

\section{INTRODUCTION}

In general, thermistors, when used as temperature measuring devices, are used singly or in pairs in some impedance net, that net being driven by some power supply, and also having an output which is monitored by a detector. Frequently the thermistor is placed at the end of a transmission line.

Errors in precision and accuracy enter from numerous sources: from thermistor drift, from the power supply or its configuration, from the detector, impedance net or transmission line, and from the calibration fit (Beck, 1956; Misener and Thompson, 1952; Muller and Stolton, 1953; Fenwal, r968[a]). It is the intent of this paper to examine instrumental parameters, and to discuss how they may be used or determined, in order to optimize the precision with which the resistance of a given thermistor in a fixed situation can be determined. These parameters include: thermistor self-heating, nominal thermistor resistance, range of application, and resolution of the detector. This examination applies equally both to the calibration of the sensor and to field measurements using it since both conditions can be completely described.

\section{TherMISTOR GHARAGTERISTICS}

Manufacturers of thermistors generally provide figures for their thermistors that indicate the ability of the device to dissipate power $P$ into the surrounding medium. This "dissipation constant" $D_{\mathrm{c}}$ is specifically defined as the amount of power required to raise the temperature of the thermistor I deg above the ambient temperature $T$. More conveniently

$$
D_{\mathrm{c}}=\frac{\mathrm{d} P}{\mathrm{~d} \Delta T}=\frac{P}{\Delta T}
$$

where $\Delta T$ is the magnitude of thermistor self-heating. In ice, for spherical thermistors (Carslaw and Jaeger, r959),

$$
D_{\mathrm{c}}=4 \pi k_{\mathrm{i}} r_{\mathrm{t}}
$$

where $k_{\mathrm{i}}$ is the thermal conductivity of ice and $r_{\mathrm{t}}$ is the radius of the thermistor. Equation (I) clearly depends on the environment of the thermistor. Manufacturers' figures are usually 
given for the thermistor in still air. In ice $D_{\mathrm{c}}$ is at least a factor of three greater, and although increases in $D_{\mathrm{c}}$ will improve the measurement precision, a factor of three in $D_{\mathrm{c}}$ results in no more than $\mathrm{I} .5 \mathrm{~dB}$ improvement in precision. Hence, for the examples used here, manufacturers' figures will be used.

Thermistors have negative thermal coefficients of resistivity, which shall be called $R_{T}$. For most thermistors

$$
R_{T} \approx 0.04 \mathrm{deg}^{-1}
$$

and this figure will be used in all of the examples (Jessop and Judge, r974).

The "time constant" of a thermistor, as defined by some manufacturers is the time required for a thermistor to change its temperature $63 \%$ of the amount of temperature change of a value impressed upon it in a step change (Fenwal, I968[b]). For a given thermistor, this may vary from fractions of seconds to minutes as a function of environment. For steady-state temperature measurements, a more useful time constant would be the time required for a thermistor to reach $63 \%$ of $\Delta T$ above $T$, from the initiation of power, but because of the effects of environment on $D_{\mathrm{c}}$ and hence $\Delta T$, and also consideration of the fact that the two constants as defined here are probably closely related, the latter time constant is almost certainly indeterminable, especially if the thermistor were deployed in a bore hole in ice.

The best that should be said about a thermistor being used to measure a steady-state temperature is that the temperature it measures is between $T$ and $T+\Delta T$. It is necessary, then, that the allowable error due to self-heating must be the full value of $\Delta T$, and that in most cases this will not be reached. It may be possible to determine $D_{\mathrm{c}}$ by measuring resistance $R$ as a function of $P$ for large values of $P$, but the advantage of knowing $D_{\mathrm{c}}$ accurately is offset by the relatively large $P$ required to take advantage of the information.

\section{BRIDGES}

The simplest type of resistance-measuring device consists of a current source driving the unknown resistance. A voltmeter then measures the voltage drop across the resistance. A measure of the signal available is $\mathrm{d} V / \mathrm{d} R$. In this case

$$
\frac{\mathrm{d} V}{\mathrm{~d} R}=i
$$

All analog ohmmeters and digital ohmmeters work in this fashion. The difficulties involved in taking this approach is that analog meters rarely have enough dynamic range or precision to be useful as high-precision instruments, and the long-term linearity and short-term thermal stability of digital meters are generally not good enough for the overall accuracy to approach the resolving capability of the instrument. This is particularly the case when different instruments are used for calibration and field measurements.

Null detectors have the advantage that they do not require the dynamic range or linearity of the "ohmmeter" type of instrument. However, they may still be thermally sensitive, and they often cannot be used for long-term unattended measurements. This is a problem if measurements continuous in time are required over a large temperature range. For making single measurements of steady-state or slowly varying temperatures, null detectors are well suited. A typical configuration is a Wheatstone bridge with the four arms equal. In this case if the bridge voltage is $V_{\mathrm{B}}$

$$
\frac{\mathrm{d} V}{\mathrm{~d} R}=\frac{V_{\mathrm{B}}}{{ }_{4} R} .
$$

If power dissipated in the thermistor is the same in both cases

$$
i^{2} R=\frac{V_{\mathrm{B}^{2}}}{4 R}
$$


and ratios of signal to power may be compared. It follows that the ratio of signal to power voltage for the first case is twice that for the second case. Difficulties in constructing relatively noiseless current sources would probably counter the advantages of one case over the other. For this reason the null detector will be considered here.

\section{Resolution}

Let $\Delta T^{\star}$ be the desired temperature resolution. Then

$$
\frac{\Delta R}{R}=\Delta T^{\star} R_{T}
$$

where $\Delta R$ is the necessary resolution in terms of resistance. From Equations (5) and (7)

$$
\frac{V_{\mathrm{B}}}{\Delta V}=\frac{4}{\Delta T^{\star} R_{T}}
$$

where $\Delta V$ is the required voltage resolution of the detector.

Power from the bridge due to Johnson noise is ideally

$$
P_{\mathrm{n}}=\frac{V_{\mathrm{n}^{2}}}{R}={ }_{4} k T B
$$

where $V_{\mathrm{n}}$ is noise voltage, $k$ is Boltzmann's constant, $T$ is the absolute temperature, and $B$ is the bandwidth of the detector. A convenient measure of the quality of the detector may be defined as the noise figure

$$
S_{\mathrm{n}}=\frac{\Delta V}{V_{\mathrm{n}}}
$$

where $\Delta V$ now represents the detector's best resolving ability. Recall from Equation (6) that

$$
P=\frac{V_{\mathrm{B}}^{2}}{{ }_{4} R} \text {. }
$$

From Equations (6), (8), (9) and (10)

$$
\Delta T^{\star}=\left(\frac{\mathrm{I} 6 S_{\mathrm{n}^{2}} k T B}{P R_{T^{2}}}\right)^{\frac{1}{2}} .
$$

But from Equation (I)

$$
P=\Delta T D_{\mathrm{c}}
$$

a minimum of the sum of $\Delta T$ and $\Delta T^{\star}$ occurs at

$$
\frac{\Delta T^{\star}}{2}=\Delta T \text {. }
$$

It follows from Equations (I I), (I2) and (13) that

$$
\begin{aligned}
\Delta T & =\left(\frac{4 S_{\mathrm{n}}{ }^{2} k T B}{D_{\mathrm{c}} R_{T^{2}}}\right)^{\frac{1}{3}}, \\
\Delta T^{\star} & =\left(\frac{32 S_{\mathrm{n}}{ }^{2} k T B}{D_{\mathrm{c}} R_{T^{2}}}\right)^{\frac{1}{3}}, \\
\Delta T+\Delta T^{\star} & =\left(\frac{\mathrm{I} 08 S_{\mathrm{n}}{ }^{2} k T B}{D_{\mathrm{c}} R_{T^{2}}}\right)^{\frac{1}{3}} .
\end{aligned}
$$

Equations (I4), (I5) and (I6) are useful for determining the optimum resolution of any system as the parameters approach the ideal. More realistically it would be convenient to 
have an expression for the optimum in terms of the detector resolution $\Delta V$. From Equations (9), (10), (14), (15) and (16)

$$
\begin{aligned}
\Delta T & =\left(\frac{\Delta V^{2}}{R D_{\mathrm{c}} R_{T^{2}}}\right)^{\frac{1}{3}}, \\
\Delta T^{\star} & =\left(\frac{8 \Delta V^{2}}{R D_{\mathrm{c}} R_{T^{2}}}\right)^{\frac{1}{3}}, \\
\Delta T+\Delta T^{\star} & =\left(\frac{27 \Delta V^{2}}{R D_{\mathrm{c}} R_{T^{2}}}\right)^{\frac{1}{3}} .
\end{aligned}
$$

From Equations (I7), (I8) and (I9) detector parameters and power levels may be optimized, and overall accuracies known. Consider for example a thermistor with $D_{\mathrm{c}}=\mathrm{I} \mathrm{mW} \mathrm{deg}^{-1}$ which is to be operated at ro $\mathrm{k} \Omega$. Suppose our detector has an input noise voltage of I $\mu \mathrm{V}$. Then

$$
\Delta T+\Delta T^{\star} \approx 0.00 \mathrm{I} \text { deg. }
$$

Here signal power has been assumed to be equal to noise power. Generally it would be desirable to have signal-to-noise ratios of at least ro $\mathrm{dB}$. Then

$$
\Delta T+\Delta T^{\star} \approx 0.0023 \mathrm{deg} .
$$

If a D.C. bridge is used with a good detector (e.g. Analog Devices chopper amp. Model $260 \mathrm{~K}$ ) it would have input noise on the order of $\mathrm{I} \mu \mathrm{V}$ P-P with a bandwidth to Io $\mathrm{Hz}$. Since a reasonable response time is desirable, a bandwidth of $5 \mathrm{~Hz}$ is minimal. Input noise voltage drift of o. I $\mu \mathrm{V} \mathrm{deg}^{-1}$ would boost effective input voltage noise to about $3.5 \mu \mathrm{V}$. This would boost a usable $\Delta V$ to I $2 \mu \mathrm{V}$, and in our example

$$
\Delta T+\Delta T^{\star} \approx 0.0054 \text { deg. }
$$

This may be considered a practical limiting accuracy for a thermistor with $D_{\mathrm{c}}=\mathrm{I} \mathrm{mW} \mathrm{deg}^{-\mathrm{I}}$ and $R=$ ıo $\mathrm{k} \Omega$, when driven by a D.C. system.

Other difficulties involved in using a D.C. system arise from thermal voltage offsets, and from the proximity of $5^{\circ} \mathrm{Hz}$ or $60 \mathrm{~Hz}$ sources. The first may be helped by selecting a chopperstabilized detector or similar detector designed for thermal immunity and by careful circuit design. The second, which may be large enough to obscure measurements in spite of a sharp roll-off, should be helped by using good shielding and grounding (the most likely mechanism would be that the transmission line, acting like an antenna, would provide sufficient commonmode signal to overload the detector input).

It is possible to obtain amplifiers which operate at audio frequencies, that have considerably less input noise voltage per unit bandwidth than D.C. amplifiers. Detectors, either phase-locked, or simple, are easily designed. Bandwidths may be limited to less than $\mathrm{Ioo} \mathrm{Hz}$, which will keep input noise voltage well below the best available D.C. detectors. For systems where extremely high precision is necessary, the designer may consider using an A.C. voltage source to feed his bridge. However, new design problems accompany the choice of an A.C. source. The operating frequency should be kept as low as possible. The reason is twofold: first, since a low bandwidth is desirable, a low center frequency would minimize the need for a large $Q$; second and predominant, the effects of stray reactance in the bridge, and particularly in the transmission line to the thermistor, would be minimized. Below $100 \mathrm{~Hz}$ flicker noise predominates and all the difficulties of D.C. bridges ensue (Letzter and Webster, 1970).

\section{Line effects}

It is usually possible to determine the resistance of the transmission line being used, or at least get an estimate well within the required accuracy. This may then be corrected for when determining the actual thermistor resistance. If a three- or four-wire transmission line is used, the problem can be eliminated entirely (Jessop, r964). 
It is desirable to know what is the maximum capacitance $C$ of the transmission line which will still permit a null of amplitude $\Delta V$. If $C$ is sufficiently small, then its effect is to shift the phase of the current, amplitude changes being second order. The constraint on $C$ is

$$
\omega R C<\frac{\Delta V}{V_{\mathrm{B}}} .
$$

If the detector is phase-locked then the observed resistance $R_{0}$ is related to the actual resistance $R_{\mathrm{a}}$ by

$$
R_{\mathrm{o}}=\left|\frac{\mathrm{I}}{j \omega C}\right|\left|R_{\mathrm{a}}\right| .
$$

To a first approximation

$$
\Delta R=R_{\mathrm{a}}-R_{0} \approx \frac{R}{2}(\omega R C)^{2}
$$

provided the transmission line is short (this error will usually be sufficiently small that an estimate of $C$ will yield a correction $\Delta R$ of sufficient accuracy). For long transmission lines null information may be coded into a frequency-modulated or pulse-coded signal (private communication from R. Goodman). Numerous sophisticated measurement systems exist, some of which combine D.C. and A.C. bridge power (Beck, I963; Greenhill and Whitehead, I949).

Evaluation of digital multimeters

On the basis of Equation (I 2) and the relation of $\Delta T^{\star}$ to $P$ (from Equations (9), (I0) and (I I))

$$
\Delta T^{\star}=\frac{2 \Delta V}{R_{T}(P R)^{\frac{1}{2}}} .
$$

It is possible to evaluate and compare measurement systems for a given $R$ and $D_{\mathrm{c}}$ (Garfinkel, 1974).

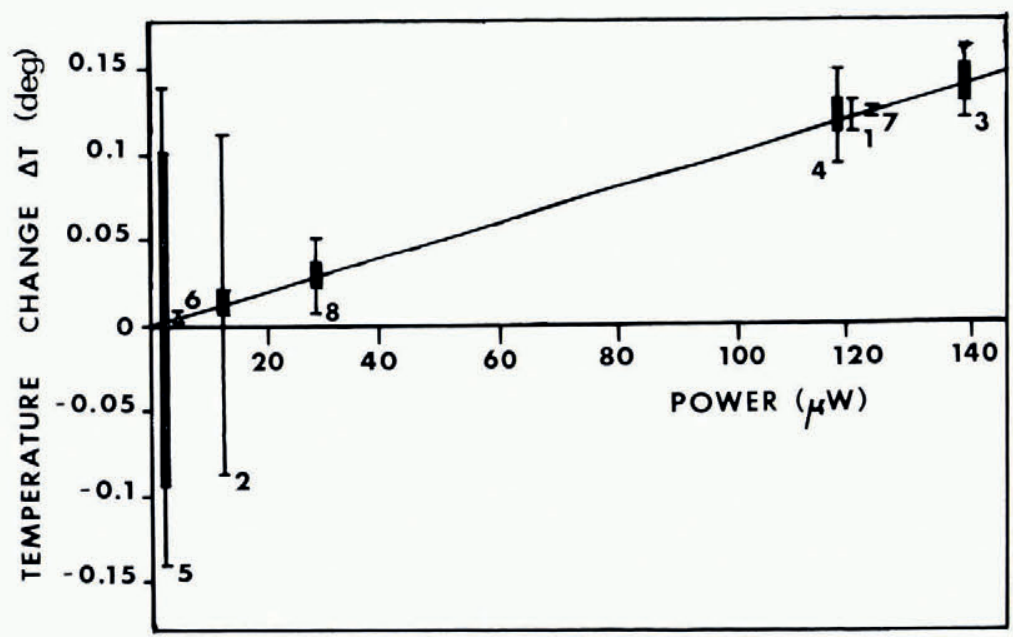

Fig. I. Errors in temperature measurement as a function of power to a Fenwal GB $34 P_{2}$ thermistor, for seven digital voltmeters. The diagonal line represents thermistor self-heating. The thin error bars represent the meter accuracy. The thick error bars represent the meter resolution. The numbers indicate the points plotted from Table I. 
TAble I. Digital multimeter errors

Data lines followed by numbers are graphed for comparison in Figure I. $\Delta T^{\star}(\mathrm{I})$ is the resolution determined by the number of available digits. $\Delta T^{\star}(2)$ is the effective guaranteed accuracy of the meter.

Unit

Fluke 8 rooA

Data precision 245

Danameter 2000

Fluke 80ooA

Systron Donner 7050

Systron Donner 7205

Systron Donner 7005

Rang
$\mathrm{k} \Omega$
$\mathrm{I} 2$
120
20
20
20
150
130
13
130
13

Power
$\mu \mathrm{W}$
120
13
1300
140
120
1.2
1.2
120
30
3000

$\Delta T$
deg
0.12
0.013
1.3
0.14
0.12
0.001
0.001
0.12
0.03
3

$\Delta T^{\star}(\mathrm{I})$
$\quad \operatorname{deg}$
0.002
0.02
0.002
0.02
0.02
0.2
0.002
0.0002
0.02
0.002

$\begin{array}{ll}\Delta T^{\star}(2) & \\ \operatorname{deg} & \\ 0.02 & \text { I } \\ 0.2 & 2 \\ 0.1 & \\ 0.04 & 3 \\ 0.06 & 4 \\ 0.28 & 5 \\ 0.01 & 6 \\ 0.001 & 7 \\ 0.04 & 8 \\ 0.004 & \end{array}$

The following digital multimeters have been evaluated in Figure I and Table I as thermistor measurement systems with respect to thermistor self-heating, displayed precision, guaranteed acccuracy, each when used with a Fenwal $\mathrm{GB}_{34} \mathrm{P}_{2}$ thermistor - $\mathrm{Io} \mathrm{k} \Omega<R<$

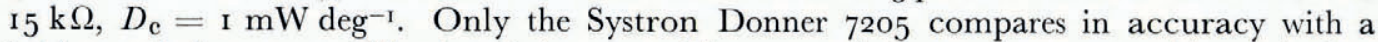
bridge and chopper-stabilized null detector. However other meters may provide equivalent accuracy for thermistors with different values of $R$ and $D_{\mathrm{c}}$.

\section{REFERENCES}

Beck, A. E. 1956. The stability of thermistors. Journal of Scientific Instruments, Vol. 33, No. 1, p. 16-18.

Beck, A. E. I 963 . Lightweight borehole temperature measuring cquipment for resistance thermometers. Journal of Scientific Instruments, Vol. 40, No. 9, p. $45^{2-54}$.

Carslaw, H. S., and Jaeger, J. C. 1959. Conduction of heat in solids. Second edition. Oxford, Clarendon Press.

Fenwal. I968[a]. Stability and reliability characteristics. Framingham, Mass., Fenwal Electronics, Inc. (Thermistor Technical Data, TD-I.)

Fenwal. I968[b]. Thermistor manual. [Framingham, Mass., Fenwal Electronics, Inc.] (EMC-5.)

Garfinkel, C. L. 1974. How to match readouts to temperature transducers. Electronics, Vol. 47, No. 24 , p. 11 7-23.

Greenhill, E. B., and Whitehead, J. R. 1949. An apparatus for measuring small temperature changes in liquids. Journal of Scientific Instruments, Vol. 26, No. 3, p. 92-95.

Jessop, A. M. 1964. A lead-compensated thermistor probe. Journal of Scientific Instruments, Vol. 41, No. 8, p. 503-04.

Jessop, A. M., and Judge, A. S. 1974. Temperature measurement in boreholes for the mining industry. Ottawa, Dept. of Energy, Mines and Resources. Earth Physics Branch. Division of Seismology.

Letzter, S., and Webster, N. 1970. Noise in amplifiers. IEEE Spectrum, August i970, p. 67-75.

Misener, A. D., and Thompson, L. G. D. 1952. The pressure coefficient of resistance of thermistors. Canadian Journal of Technology, Vol. 3o, No. 4, p. 89-94.

Muller, R. H., and Stolton, H. J. i 953 . Use of thermistors in precise measurements of small temperature differences. Analytical Chemistry, Vol. 25, No. 7, p. $1103^{-06}$.

\section{DISGUSSION}

W. D. Harrison: Is it not true that some of the self-heating error can be calibrated away? B. B. NARoD: Some of it can, but if the calibration conditions are significantly different from the conditions of measurement that affects the issue. If an accuracy of o.o I deg is adequate, I should like to be able to ignore this problem, and I think I can.

K. Philberth: Aging is a serious problem in cases where the thermistor cannot be retrieved and recalibrated after the measurements. Could you provide some information about which companies give the most reasonable and reliable guarantees on aging deviation of their thermistors? 
NAROD: I agree that thermistor stability is a serious problem. It appears, though, that stability is also a problem of manufacture quality control, so that the best thermistors now may not be as good if produced sometime in the future. I have worked with only two manufacturer's, Fenwal and YSI, and on the average they are comparable. Stability can be effected by size as well; the smallest bead thermistors at present being the best compromise.

A. E. BECK: What do you do about cable series and shunt resistances and their variations when using digital multimeters to measure the resistance? Or are you using a lead compensated bridge?

NAROD: The errors introduced by the multimeters are in the order of o. I deg and this masks any effect, but we are proposing to change to a more accurate system. We shall use a fourconductor cable and measure the resistance in situ.

Another problem is the effect of pressure on thermistors. Work to date indicates that the effect worsens as temperature decreases. If you are interested in 0.1 deg accuracy, the effects are unimportant. But for o.or deg accuracy they show up for pressures corresponding to the depths at which we are setting thermistors in the glaciers. It would be good to recover thermistors for recalibration but that is usually impossible.

HARRISON: I have done it by putting additional conductors in the cable and passing current down them to melt out the cable. 